\title{
Synthesis and Characterization of Some Adducts of $O$-Hexyl Dithiocarbonates of Nickel(II) with Heterocyclic Amines
}

\author{
SHIVANGI SHARMA ${ }^{1}$, RENU SACHAR $^{1}$, G.D. BAJJU ${ }^{1}$ and VIKAS SHARMA ${ }^{2}$ \\ ${ }^{1}$ Department of Chemistry, University of Jammu, Baba Saheb Ambedkar Road, \\ Jammu -180006, J \& K, India \\ ${ }^{2}$ Division of Biochemistry, Faculty of Basic Sciences, SKUAST of Jammu, Main Campus \\ Chatha, Jammu-180009, J \& K, India \\ sharmashivangi8618@gmail.com
}

Received 20 December 2017 / Accepted 10 January 2018

\begin{abstract}
A series of adducts of $o$-hexyl dithiocarbonate of nickel(II) $\left[\left(\mathrm{C}_{6} \mathrm{H}_{13} \mathrm{OCS}_{2}\right)_{2} \mathrm{Ni}\right]$ have been synthesized in 1:2 molar ratio by the reaction of aqueous solution of $\mathrm{NiCl}_{2} \cdot 6 \mathrm{H}_{2} \mathrm{O}$ with aqueous solution of potassium salt of $o$-hexyl dithiocarbonate. These complexes were further reacted with nitrogen donor ligands to obtain donor stabilized complex of the type $\left[\left(\mathrm{C}_{6} \mathrm{H}_{13} \mathrm{OCS}_{2}\right)_{2} \mathrm{Ni.nL}\right.$, ( $\mathrm{L}=2-, 3-, 4-$ cyanopyridines and 2-,3-,4-aminopyridines, $\mathrm{n}=2$ ). These adducts were characterized by elemental analysis, molar conductance, magnetic susceptibility measurements, IR and electronic spectral studies. The spectral studies revealed the trans octahedral geometry of the adducts around the Ni(II) metal ion. All the adducts were paramagnetic and non-electrolytic in nature. These complexes have also depicted the potential antifungal activity against the fungus Curvularia lunata.
\end{abstract}

Keywords: Nickel(II), $O$-hexyl dithiocarbonate, Curvularia lunata, Nitrogen donor ligands

\section{Introduction}

Xanthates, also known as $o$-alkyl/aryl dithiocarbonates, are one of the important members of 1,1-dithiolate family. Xanthates have been known for a long time ${ }^{1,2}$ and many adducts of metal xanthates with different ligands have been prepared studied in the last several decades ${ }^{3,4}$. Xanthates of certain transition metals are used as accelerators in vulcanization of rubber, brought a new revolution in rubber industry ${ }^{5}$. Xanthates form a chelate with virtually all transition elements and has proved to be a versatile chelating agent for the separation and extraction of metal in analytical chemistry and mineral floating ${ }^{6,7}$. Xanthates have recently been shown to inhibit the replication of both DNA and RNA viruses in vitro. It was found that certain xanthate derivatives exhibit beneficial antimicrobial and antiviral effects ${ }^{8}$. In the present research work, we are reporting the synthesis and characterization of 1:2 adducts of $o$-hexyl dithiocarbonate of nickel(II) with substituted heterocyclic amines such as 2-,3-,4- cyanopyridines and 2-,3-,4-aminopyridies. 


\section{Experimental}

Potassium salt of hexyl xanthate was prepared by the method reported in literature ${ }^{9}$. In a $400 \mathrm{~mL}$ round bottomed flask, fitted with a reflux condenser, was placed $42 \mathrm{~g}(0.75 \mathrm{~mol})$ of potassium hydroxide pellets and $265.66 \mathrm{~g}(323.9 \mathrm{~mL}, 2.6 \mathrm{~mol})$ of $n$-hexanol was added. The reaction mixture was heated under reflux for $1 \mathrm{~h}$. The mixture was then cooled and liquid from residual solid was decanted off into another dry $500 \mathrm{~mL}$ flask. To this flask, was added $52 \mathrm{~g}(45 \mathrm{~mL}, 0.75 \mathrm{~mol})$ of carbon disulphide slowly with constant shaking. The residual solid mass was filtered (after cooling in ice) on a sintered glass funnel at the pump. It was washed with three $25 \mathrm{~mL}$ portions of ether. The resulting potassium $o$-hexyl dithiocarbonate (potassium salt of hexyl xanthate) was dried in a vaccum desiccator over anhydrous calcium chloride. It was then recrystallized from absolute ethanol.

\section{Preparation of bis (O-hexyl dithiocarbonato)nickel(II)}

The saturated aqueous solution of hydrated nickel chloride, $\mathrm{NiCl}_{2} \cdot 6 \mathrm{H}_{2} 0(2.37 \mathrm{~g}, 0.01 \mathrm{~mol})$ and potassium $o$-hexyl dithiocarbonate $(4.32 \mathrm{~g}, 0.02 \mathrm{~mol})$ were prepared separately and then mixed with constant stirring. Dark green precipitates were formed which were filtered immediately and were dried in a vaccum desiccator over anhydrous calcium chloride. The composition of the complex was established to be $\mathrm{Ni}\left[\mathrm{S}_{2} \mathrm{C}\left(\mathrm{O}-\mathrm{C}_{6} \mathrm{H}_{13}\right)\right]_{2}$ by the elemental analysis.

\section{Preparation of 1:2 adducts of bis(O-hexyl dithiocarbonato)nickel(II) with substituted} heterocyclic amines

1:2 Addition complexes of bis( $o$-hexyl dithiocarbonato)nickel(II) with substituted heterocyclic amines were prepared by stirring $\mathrm{Ni}\left[\mathrm{S}_{2} \mathrm{C}\left(\mathrm{O}-\mathrm{C}_{6} \mathrm{H}_{13}\right)\right]_{2}(1.073 \mathrm{~g}, 0.0026 \mathrm{~mol})$ in acetone with heterocyclic amines [2-,3-,4-cyanopyridine $=0.541 \mathrm{~g}$ each; 2-,3-,4- aminopyridine $=0.489 \mathrm{~g}$ each $(0.0052 \mathrm{~mol})]$ for $30 \mathrm{~min}$. The contents of the reaction mixture were allowed to stand for 20-24 $\mathrm{h}$ and the green adduct obtained was washed with the solvent used in their preparation and dried over calcium chloride at room temperature (Scheme 1).

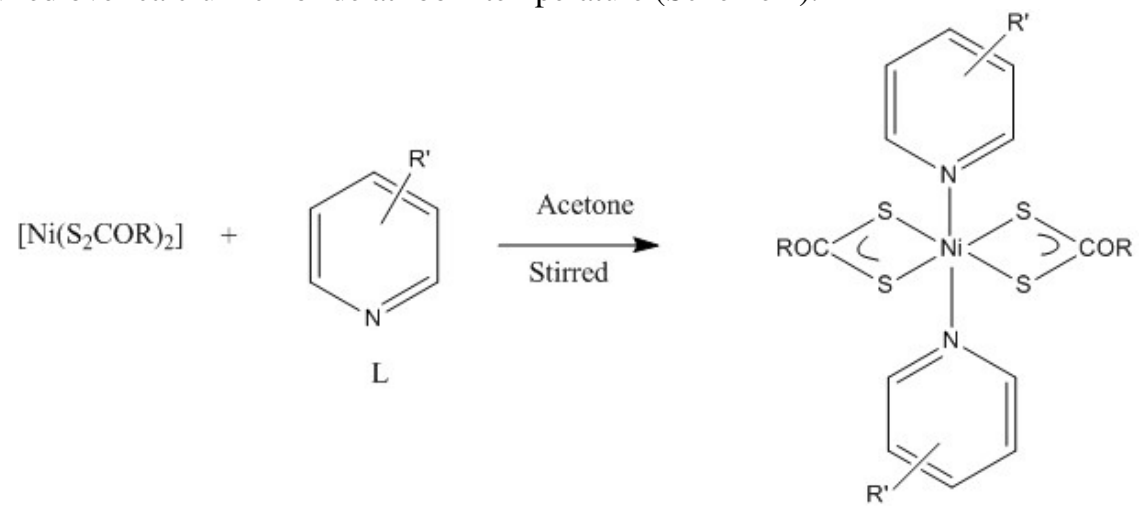

Where $\mathrm{R}=\mathrm{C}_{6} \mathrm{H}_{13} ; \mathrm{L}=2$-,3-,4-cyanopyridines; 2-,3-,4-aminopyridines; $\mathrm{R}^{\prime}=\mathrm{CN}$ or $\mathrm{NH}_{2}$

Scheme 1. Method of preparation and proposed structure of 1:2 adducts

\section{Methods}

Carbon, hydrogen, nitrogen and sulfur were determined on elemental analyzer (CNN5-932, LECO Corporation, USA). Molar conductance was determined on their millimolar solutions in DMF using digital conductivity meter (century CC601). Magnetic moments were determined at room temperature by Gouy's method on magnetic susceptibility balance. 
Infrared spectra of the complexes over the region 4,000-400 $\mathrm{cm}^{-1}$ were recorded using $\mathrm{KBr}$ pellets on infrared spectrophotometer (Perkin Flmer FT-IR). The electronic spectra of the adducts were recorded in DMF in the range $12500 \mathrm{~cm}^{-1}$ to $40000 \mathrm{~cm}^{-1}$ on T90 + UVvisible spectrophotometer.

\section{Results and Discussion}

The adducts of bis(o-hexyl dithiocarbonato)nickel(II) are microcrystalline solids. The adducts are shining green to blackish green in color and are soluble in common organic solvents like acetone, chloroform, dimethylformamide and dimethyl sulfoxide, but they are insoluble in benzene, carbon tetrachloride, nitrobenzene and water. The elemental analysis reveals that the adducts isolated have 1:2 stoichiometry depending upon the molar ratios of metal and ligand taken for their preparation (Table 1).

Table 1. Analytical data of $1: 2$ adducts of bis(o-hexyl dithiocarbonato)nickel(II) with substituted heterocyclic amines

\begin{tabular}{cccccc}
\hline \multirow{2}{*}{ S.No. } & \multirow{2}{*}{ Name of the adduct } & \multicolumn{4}{c}{ Analysis found (calculated) \% } \\
\cline { 3 - 6 } & & $\mathrm{C}$ & $\mathrm{H}$ & $\mathrm{N}$ & $\mathrm{S}$ \\
\hline 1. & Bis(o-hexyl dithiocarbonato) & 48.33 & 4.60 & 8.06 & 20.07 \\
& bis(2-cyanopyridine)nickel(II) & $(50.26)$ & $(5.47)$ & $(9.02)$ & $(20.62)$ \\
2. & Bis( $o$-hexyl dithiocarbonato) & 49.13 & 4.77 & 8.91 & 19.50 \\
& bis(3-cyanopyridine)nickel(II) & $(50.26)$ & $(5.47)$ & $(9.02)$ & $(20.62)$ \\
3. & Bis(o-hexyl dithiocarbonato) & 49.55 & 5.09 & 8.86 & 20.12 \\
& bis(4-cyanopyridine)nickel(II) & $(50.26)$ & $(5.47)$ & $(9.02)$ & $(20.62)$ \\
4. & Bis(o-hexyl dithiocarbonato) & 46.97 & 5.83 & 8.76 & 20.68 \\
& bis(2-aminopyridine)nickel(II) & $(47.94)$ & $(6.32)$ & $(9.32)$ & $(21.3)$ \\
5. & Bis(o-hexyl dithiocarbonato) & 47.08 & 5.79 & 8.93 & 20.55 \\
& bis(3-aminopyridine)nickel(II) & $(47.94)$ & $(6.32)$ & $(9.32)$ & $(21.3)$ \\
6. & Bis( $o$-hexyl dithiocarbonato) & 47.12 & 5.90 & 9.02 & 20.70 \\
& bis(4-aminopyridine)nickel(II) & $(47.94)$ & $(6.32)$ & $(9.32)$ & $(21.3)$ \\
\hline
\end{tabular}

The structures of the isolated complexes were established from their molar conductance and magnetic susceptibility measurements, electronic and infrared spectral data. The results of these investigations are tabulated and discussed. The molar conductance values of their millimolar solutions in DMF are found in the range of $21.38-34.63 \mathrm{ohm}^{-1} \mathrm{~mol}^{-1} \mathrm{~cm}^{2}$. These values are lower than the values expected for any uni-univalent electrolyte in these solvents suggesting that these complexes are neutral and non-ionic in character (Table 2). The $\mathrm{Ni}^{2+}$ cation, being $\mathrm{d}^{8}$ cation give rise to two spin unpaired electrons per nickel(II) ion giving a spin only magnetic moment of 2.83 B.M. In octahedral complexes, the observed magnetic moments lie in the range of 2.9-3.4 B.M. These lower values of magnetic moments in octahedral complexes of nickel(II) are due to almost complete quenching of orbital contribution in these complexes ${ }^{12-14}$. The $1: 2$ adducts of nickel(II) hexylxanthate with nitrogen donors fall in the range 2.87-3.24 B.M. (Table 2). These values are in accordance with the paramagnetic nature of these adducts due to the presence of two unpaired electrons. It also suggests that the adducts of nickel(II) have six coordinated octahedral structure. The higher value of magnetic moment may be due to the orbital contribution.

The infrared spectra of the adducts of nickel(II) xanthates exhibit absorption bands for xanthate ligands at $1270-1210 \mathrm{~cm}^{-1}$ and $1140 \mathrm{~cm}^{-1}$ which have been assigned to $\mathrm{V}_{\text {as }}(\mathrm{C}-\mathrm{O}-\mathrm{C}$ ) and $\mathrm{V}_{\text {as }}(\mathrm{C}-\mathrm{O}-\mathrm{C})$ vibrations while bands at $1030-1040 \mathrm{~cm}^{-1}$ belongs to the $\mathrm{V}(\mathrm{C}-\mathrm{S})$ vibrations ${ }^{15}$. 
In the free aminopyridine ligands N-H streching frequencies fall at 3450,3350 and $3175 \mathrm{~cm}^{-1}$ for 2-aminopyridine; 3335 and $3205 \mathrm{~cm}^{-1}$ for 3-aminopyridine and 3320 and $3185 \mathrm{~cm}^{-1}$ for 4-aminopyridine. In case the aminopyridine coordinated to a metal through its amino nitrogen, these peaks shift to a lower position. In the complexes prepared in the present work, these vibrations showed a small position shift. In the adducts of bis $(o$-hexyl dithiocarbonato) nickel(II), these peaks appear around 3450-3465, 3350-3390 and 3180$3230 \mathrm{~cm}^{-1}$ in the adducts with 2-aminopyridines. Similarly in case of adducts with 3aminopyridines with N-H stretching frequencies occur about $3340-3370$ and $3210-3235 \mathrm{~cm}^{-1}$ in the adducts with 4-aminopyridines, the N-H stretching frequencies occur around 33253350 and $3195-3220 \mathrm{~cm}^{-1}$. The absence of negative shifts in the stretching frequencies on coordination implied that the interaction of the amino group with nickel(II) ion is ruled out. Thus, these ligands use their ring nitrogen atom for coordination to the metal ion. A negative shift is observed in $\mathrm{C}-\mathrm{H}$ out of plane vibrations of 2-,3- and 4-aminopyridine adducts which confirms that these ligands interact with the metal ion through their ring nitrogen atom.

Table 2. Molar conductance and magnetic data of 1:2 adducts of bis(o-hexyl dithiocarbonato)nickel(II) with substituted heterocyclic amines

\begin{tabular}{ccccc}
\hline S.No. & Name of the adduct & $\begin{array}{c}\text { Molar conductance } \\
\left(\mathrm{ohm}^{-1} \mathrm{~mol}^{-1} \mathrm{~cm}^{-2}\right)\end{array}$ & $\begin{array}{c}\text { Magnetic } \\
\text { data (B.M) }\end{array}$ & $\begin{array}{c}\text { Temp., } \\
\mathrm{K}\end{array}$ \\
\hline 1. & $\begin{array}{c}\text { Bis }(o \text {-hexyl dithiocarbonato) } \\
\text { bis(2-cyanopyridine)nickel(II) } \\
\text { Bis }(o \text {-hexyl dithiocarbonato) } \\
\text { bis(3-cyanopyridine)nickel(II) }\end{array}$ & 34.63 & 3.18 & 308 \\
Bis $(o$-hexyl dithiocarbonato) & 21.38 & 3.15 & 308 \\
3. & 25.50 & 3.20 & 308 \\
4is(4-cyanopyridine)nickel(II) & $\begin{array}{r}\text { Bis }(o \text {-hexyl dithiocarbonato) } \\
\text { bis(2-aminopyridine)nickel(II) }\end{array}$ & 18.33 & 2.87 & 308 \\
5. & $\begin{array}{r}\text { Bis }(o \text {-hexyl dithiocarbonato) } \\
\text { bis(3-aminopyridine)nickel(II) }\end{array}$ & 19.72 & 3.24 & 308 \\
6. & $\begin{array}{r}\text { Bis }(o \text {-hexyl dithiocarbonato) } \\
\text { bis(4-aminopyridine)nickel(II) }\end{array}$ & 19.39 & 3.17 & 308 \\
\hline
\end{tabular}

In cyanopyridines, there are two potential donor sites, the pyridine ring nitrogen and nitrile group nitrogen atom. In order to decide the coordination site in a particular cyanopyridine, a study of vibrations of pyridine ring and $\mathrm{C} \equiv \mathrm{N}$ stretching frequencies can be of much help ${ }^{16-18}$.

It is established that there should be an increase in $\mathrm{v}(\mathrm{C} \equiv \mathrm{N})$ by at least $30 \mathrm{~cm}^{-1}$ if a cyanopyridne coordinates to the metal using nitrile nitrogen atom. On the other hand if $-\mathrm{CN}$ group coordinates using $\pi$-electrons $\mathrm{v}(\mathrm{C} \equiv \mathrm{N})$ must show a negative shift ${ }^{19-21}$. The $\mathrm{C} \equiv \mathrm{N}$ stretching frequencies in free 2-,3- and 4-cyanopyridnes fall at $2268 \mathrm{~cm}^{-1}, 2240 \mathrm{~cm}^{-1}$ and $2225 \mathrm{~cm}^{-1}$ respectively but in adducts of bis( $o$-hexyl dithiocarbonato) nickel(II), these vibrations occur around $2269 \mathrm{~cm}^{-1}, 2235 \mathrm{~cm}^{-1}$ and $2236 \mathrm{~cm}^{-1}$ respectively showing no appreciable shift in $\mathrm{v}(\mathrm{C} \equiv \mathrm{N})$. (Figure 1) So, it can be concluded that 2-,3- and 4-cyanopyridines coordinate to metal through their ring nitrogen atom. The IR spectra of $1: 2$ adducts of bis( $o$-hexyl dithiocarbonato) nickel(II) with cyanopyridines and aminopyridines show absorption bands at $1210-1146 \mathrm{~cm}^{-1}$ and $1035-1082 \mathrm{~cm}^{-1}$ which are assigned to be $\mathrm{v}_{\mathrm{as}}(\mathrm{C}-\mathrm{O}-\mathrm{C}), \mathrm{v}_{\mathrm{s}}(\mathrm{C}-\mathrm{O}-\mathrm{C})$ and $\mathrm{v}(\mathrm{C}-\mathrm{S})$ stretching vibrations respectively (Table 3 ). The appearance of a single band for $\mathrm{v}(\mathrm{C}-\mathrm{S})$ its position indicates symmetrical bidentate binding of the xanthate moiety. 


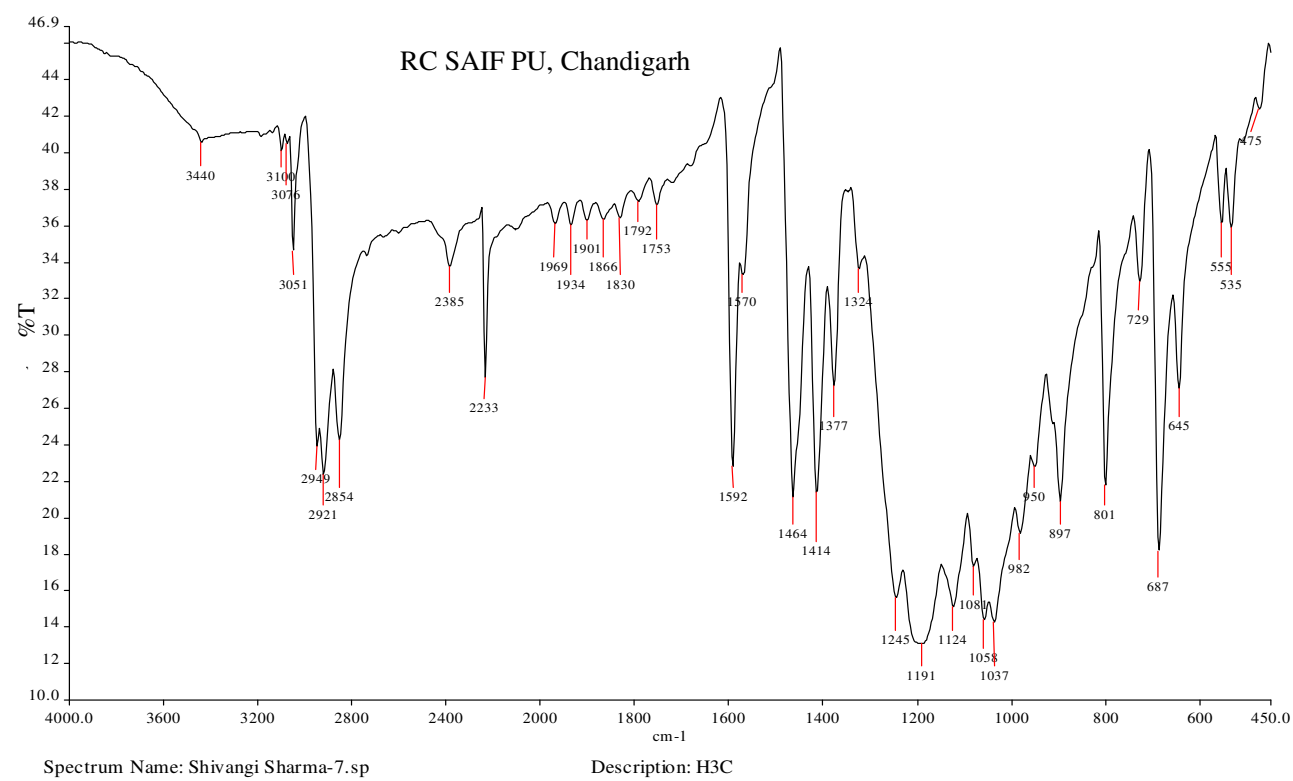

Date Created: fri may 17 12:33:55 2013 India Standard Time (GMT+5:30)

Figure 1. IR spectra of bis(o-hexyl dithiocarbonato bis(3-cyanopyridine)nickel(II)

Table 3. Infrared and electronic spectral data of 1:2 adducts of bis( $o$-hexyl dithiocarbonato) nickel(II) with substituted heterocyclic amines

\begin{tabular}{|c|c|c|c|c|c|c|c|}
\hline \multirow{2}{*}{ S.No } & \multirow{2}{*}{ Name of the adduct } & \multicolumn{3}{|c|}{$\begin{array}{l}\text { Infrared spectral data, } \\
\mathrm{cm}^{-1}\end{array}$} & \multicolumn{3}{|c|}{$\begin{array}{l}\text { Electronic spectral data, } \\
\qquad \mathrm{cm}^{-1}\end{array}$} \\
\hline & & $\begin{array}{c}\text { vas } \\
(\mathrm{C}-\mathrm{O}-\mathrm{C})\end{array}$ & $\begin{array}{c}\text { vs } \\
(\mathrm{C}-\mathrm{O}-\mathrm{C})\end{array}$ & $\begin{array}{c}\mathrm{v} \\
(\mathrm{C}-\mathrm{S})\end{array}$ & v1 & v2 & v3 \\
\hline 1. & $\begin{array}{l}\text { Bis(o-hexyl dithiocarbonato) } \\
\text { bis(2-cyanopyridine)nickel(II) }\end{array}$ & 1272 & 1126 & 1082 & 10466 & 18918 & 27672 \\
\hline 2. & $\begin{array}{l}\text { Bis(o-hexyl dithiocarbonato) } \\
\text { bis(3-cyanopyridine)nickel(II) }\end{array}$ & 1245 & 1124 & 1058 & 11671 & 18317 & 27717 \\
\hline 3. & $\begin{array}{l}\text { Bis(o-hexyl dithiocarbonato) } \\
\text { bis(4-cyanopyridine)nickel(II) }\end{array}$ & 1271 & 1128 & 1048 & 10317 & 17880 & 27875 \\
\hline 4. & $\begin{array}{l}\text { Bis(o-hexyl dithiocarbonato) } \\
\text { bis(2-aminopyridine)nickel(II) }\end{array}$ & 1264 & 1133 & 1052 & 10363 & 17388 & 26975 \\
\hline 5. & $\begin{array}{l}\text { Bis(o-hexyl dithiocarbonato) } \\
\text { bis(3-aminopyridine)nickel(II) }\end{array}$ & 1210 & 1125 & 1035 & 11896 & 17358 & 26952 \\
\hline 6. & $\begin{array}{l}\text { Bis(o-hexyl dithiocarbonato) } \\
\text { bis(4-aminopyridine)nickel(II) }\end{array}$ & 1291 & 1146 & 1052 & 11425 & 17978 & 27190 \\
\hline
\end{tabular}

The electronic spectra of the adducts of nickel(II) xanthates with substituted heterocyclic amines, prepared in the present work recorded in dimethylformamide. The electronic spectral data of the 1:2 adducts of bis(o-hexyl dithiocarbonato)nickel(II) with 
cyano and aminopyridines show these bands in the range $10317-11896 \mathrm{~cm}^{-1}, 17358-18918 \mathrm{~cm}^{-1}$ and 26952-27875 $\mathrm{cm}^{-1}$ which are assigned to ${ }^{3} \mathrm{~A}_{2 \mathrm{~g}} \rightarrow{ }^{3} \mathrm{~T}_{2 \mathrm{~g}}(\mathrm{~F})\left(\mathrm{v}_{1}\right),{ }^{3} \mathrm{~A}_{2 \mathrm{~g}} \rightarrow{ }^{3} \mathrm{~T}_{1 \mathrm{~g}}(\mathrm{~F})\left(\mathrm{v}_{2}\right)$ and ${ }^{3} \mathrm{~A}_{2 \mathrm{~g}}(\mathrm{~F}) \rightarrow{ }^{3} \mathrm{~T}_{1 \mathrm{~g}}(\mathrm{P})\left(\mathrm{v}_{3}\right)$ transitions respectively are presented in Table 3 . The appearance of these three broad bands along with shoulders show that the adducts are having trans octahedral geometry around the $\mathrm{Ni}$ (II) metal ion (Figure 2). The data is in consistent with the results for six coordinate octahedral complexes of $\mathrm{Ni}(\mathrm{II})$ ion $^{22}$.

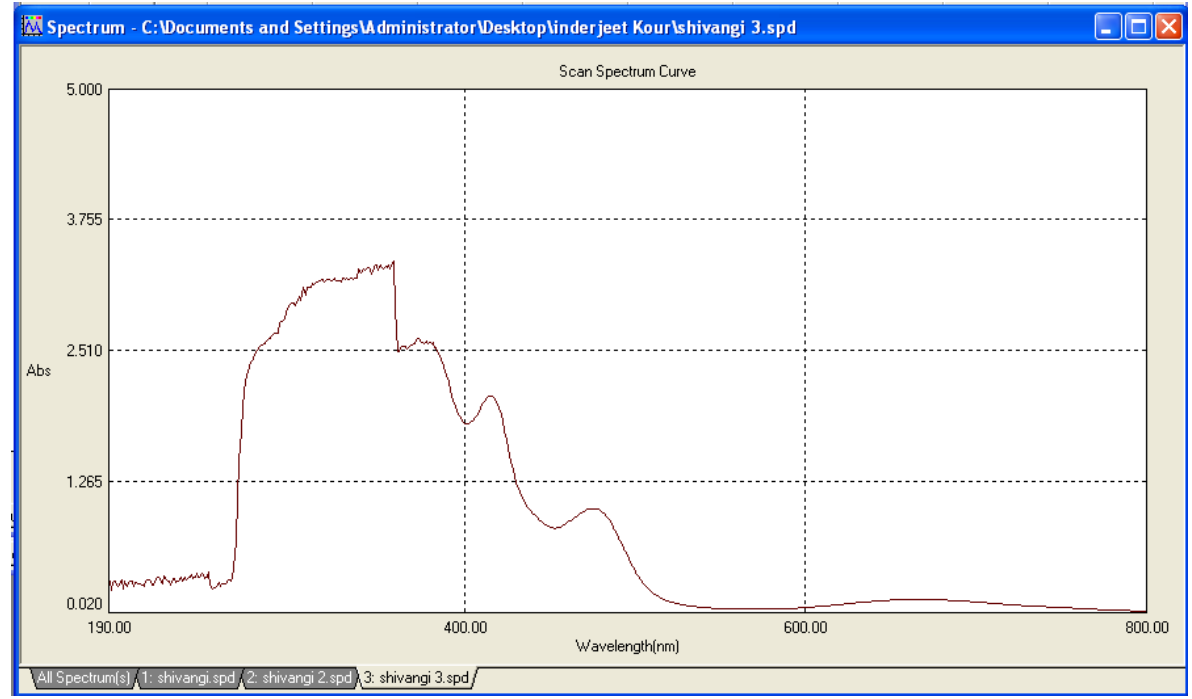

Figure 2. Electronic spectra of bis(o-hexyldithiocarbonato)bis(2-cyanopyridine)nickel(II)

\section{Antifungal studies}

The antifungal activity of the adducts was tested by poisoned food technique against the pathogenic fungus Curvularia lunata. The linear growth of the fungus in controlled manner was recorded at different concentrations of the adducts. The growth inhibition of Curvularia lunata over control was calculated (Table 4).

Table 4. In vitro evaluation of complexes against Curvularia lunata, mean colony diameter, $\mathrm{C}=90 \mathrm{~mm}$

\begin{tabular}{clccc}
\hline S.No. & Name of the adducts & $\begin{array}{c}\text { Concentration, } \\
\mathrm{ppm}\end{array}$ & $\begin{array}{c}\text { Colony } \\
\text { diameter, } \\
\mathrm{mm}\end{array}$ & $\begin{array}{c}\text { \% Inhibition } \\
(\mathrm{I})=[\mathrm{C}-\mathrm{T} / \mathrm{C}] \mathrm{x} 100\end{array}$ \\
\hline 1. & Bis(o-hexyldithiocarbonato)- & 10 & 75 & 17 \\
& bis (4-aminopyridine)nickel(II) & 100 & 38 & 58 \\
& & 200 & 14 & 84 \\
2. & Bis(o-hexyldithiocarbonato)- & 10 & 81 & 10 \\
& bis (3-cyanopyridine)nickel(II) & 100 & 67 & 26 \\
& & 200 & 50 & 44 \\
3. & Bis(o-hexyldithiocarbonato)- & 10 & 79 & 13 \\
& bis(4-cyanopyridine)nickel(II) & 100 & 64 & 29 \\
& & 200 & 52 & 42 \\
\hline
\end{tabular}


It is found that on increasing the concentration of the adducts, the colony diameter of the fungus decreases and hence percent inhibition increases ${ }^{23}$ (Figure 3a, 3b and 3c). The growth inhibition of fungus over control was calculated as:

$$
\% \text { Inhibition }(\mathrm{I})=[\mathrm{C}-\mathrm{T} / \mathrm{C}] \times 100
$$

Where $\mathrm{I}=$ percent inhibition, $\mathrm{C}=$ mean growth of fungus (in $\mathrm{mm}$ ) in control and $\mathrm{T}=$ mean growth of fungus (in $\mathrm{mm}$ ) in treatment.

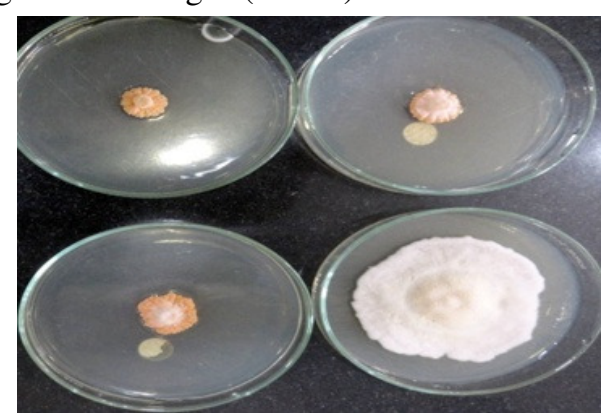

Figure 3(a). Antifungal activity of bis $(o-$ hexyldithiocarbonato)bis(4-aminopyridine)nickel(II)



Figure 3(b). Antifungal activity of bis $(o-$ hexyldithiocarbonato)bis(3-cyanopyridine)nickel(II)

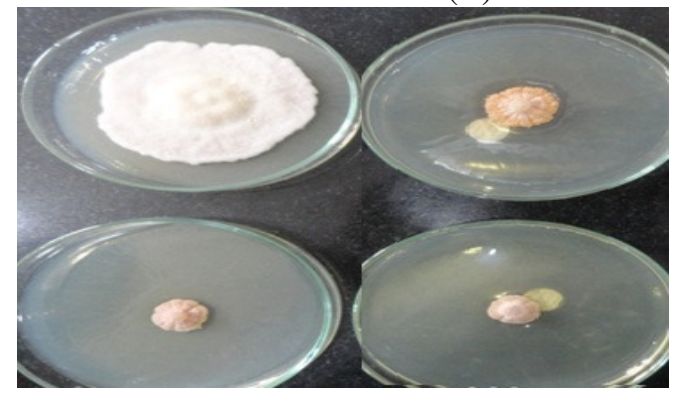

Figure 3(c). Antifungal activity of bis(o-hexyldithiocarbonato)bis(4-cyanopyridine)nickel(II)

\section{Conclusion}

On the basis of above studies, it is found that 1:2 adducts of $\mathrm{Ni}$ ( $o$-hexyldithiocarbonato $)_{2}$ have trans octahedral geometry. The complexes analyzed are paramagnetic in nature and they show considerable antifungal activity.

\section{References}

1. Coucouvanis D, In Lippard S J, (Ed.), Progress in Inorganic Chemistry, Interscience, New York, 1970, 11, 233.

2. Eisenberg R, In Lippard S J, (Ed.), Progress in Inorganic Chemistry, Interscience, New York, 1970, 12, 295.

3. Cras J A and Willemse J, In: Wilkinson G, Gillard R D and McCleverty J A, (Eds.), Comprehensive Coordination Chemistry, 1987, 2, Pergamon Press, Oxford, 579.

4. Haiduc I, In: McClevery J A, Mayer T J and Lever A B P (Eds.), Comprehensive Coordination Chemistry II, 2004, 1, 349.

5. Palaty S, Devi P V and Joseph R, J Appl Polym Sci., 2011, 122(2), 1325-1332; DOI:10.1002/app.34057 
6. Gimeno M C, Jambrina E, Laguna A, Laguna M, Murray H H and Terroba R, Inorg Chim Acta, 1996, 249(1), 69-73; DOI10.1016/0020-1693(96)05027-X

7. Allen F H and Kennard O, Chem Des Autom News, 1993, 8, 31-37.

8. Friebolin W, Schilling G, Zoller M and Amtmann E, J Med Chem., 2005, 48(25), 7925-7931; DOI:10.1021/jm0408991

9. Furniss B S, Hamaford AJ, Smith P W G and Tatchell A R, Vogel's Textbook of Practical Organic Chemistry, Pearson Education, London, UK, $5^{\text {th }}$ Edition, 1989.

10. Martin R L and Whitley A, J Chem Soc., 1958, 52, 1394

11. Lever A B P, J Inorg Nucl Chem., 1965, 27(1), 149-153; DOI:10.1016/00221902(65)80204-4

12. Heslop PB and robinson PL, "Inorganic Chemistry", Elsevier publishing Co, New York, 1967.

13. Schniedre P W, Phelan P F and Hapern J, J Am Chem Soc., 1969, 91(1), 77-81; DOI:10.1021/ja01029a016

14. Cotton F A and Fackler J P, J Am Chem Soc., 1961, 83(18), 3775-3778; DOI:10.1021/ja01479a011

15. Zagal J and Costamagna J A, J Inorg Nucl Chem Lett., 1971, 13(9), 411-416; DOI:10.1016/0020-1650(77)80030-5

16. Gill N S, Natal R H, Scaife D E and Sharp D W A, J Inorg Nucl Chem., 1961, 18, 7987; DOI:10.1016/0022-1902(61)80372-2

17. Goldstein M, Mooney E F, Anderson A and Gebbie H A, Spectrochim Acta, 1965, 21(1), 105-117; DOI:10.1016/0371-1951(65)80109-6

18. Postmus C, Ferraro J R and Wozniak W, Inorg Chem., 1967, 6(11), 2030-2032; DOI:10.1021/ic50057a021

19. Ford P C and Clarke R E, Chem Commun., 1968, 62, 1109.

20. Farona M F and Brewer N J, J Am Chem Soc., 1966, 88(16), 3735-3737; DOI:10.1021/ja00968a011

21. Jain S C and Rivest R, Can J Chem., 1967, 45(2), 139-145; DOI:10.1139/v67-029

22. Lever A B P, Inorg Elect Spectro., Elsevier, 1984, 33, 507.

23. Nene Y L and Thapliyal P N, Fungicides in Plant Diseases Control, III Edn., 1993, 691. 